\title{
Impact of the operating time and loading of an engine with spark ignition powered with biogas on selected parameters of engine oil
}

\author{
Jerzy Kaszkowiak ${ }^{1, *}$, Marietta Markiewicz-Patalon ${ }^{1}$, and Ewa Kaszkowiak ${ }^{1}$ \\ ${ }^{1}$ UTP University of Science and Technology, 85-796 Bydgoszcz Al. S.Kaliskiego 7 Poland
}

\begin{abstract}
Engines powered with biogas obtained from wastes obtained from a municipal waste water treatment plant were subject to studies. The engines powered the electric current generators. It was found, that after 800 operating hours, differentiation in the contents of iron, zinc and copper depending on the mode of their loading occurred in the engine oil. In the group of engines loaded in about $60 \%$ of power, higher contents of iron, copper and zinc in the engine oil than in the engines loaded in $85 \%$ of power, was found. Occurrence of other statistically important differences in the contents in oil of manganese, chromium and aluminum was found.
\end{abstract}

\section{Introduction}

The use of biogas as the source of energy is the manner both for lowering of the level of consumption the fossil energy sources, as well as for the biological wastes' recycling. Biogas may be generated from plant products cultivated specially for the power purposes. It is a high-yield manner, however it requires designation for production of the cultivation areas on which food may be produced [1]. Also, seasonal availability of plant substrates requiring their preservation and necessity of their preparation already at the harvesting level, is its disadvantage. It requires more intensive shredding of the harvested plants, what results in the increase of power outlays [2, 3]. Biogas' generation is possible also from organic wastes [4]. Depending on substrate, the generated biogas may have different composition. Generation of biogas is possible also from municipal wastes, remains from animal production. More and more often there is also the use of seal plants (algae) for biogas generation. The composition of the obtained biogas depends on the used substrate and there occurs a relatively high variability of biogas' composition. The biggest differentiation occurs in the content of methane. The scope of the biogas' composition for selected substrates is presented in the table 1. For direct combustion and use as a source of heat, biogas is most often not purified, but in case of its use as a fuel for combustion engines, its purification is required [5]. The engines with spark ignition powered with biogas, belong to a special group of units. They are most often used as power transmissions in cogeneration systems. Such a manner of biogas' use enables both easy transfer of power with the use of power networks as well as for temporary storing in tanks with the possibility of their later usage. Supplementation of possible biogas' shortages for powering of cogeneration units with natural gas is often used.

Table 1. Composition of biogas depending on the substrate from which it has been generated.

\begin{tabular}{|c|c|c|}
\hline $\begin{array}{c}\text { Source } \backslash \\
\text { Compon } \\
\text { ent }\end{array}$ & $\begin{array}{c}\text { From power } \\
\text { plants }\end{array}$ & $\begin{array}{c}\text { Waste water } \\
\text { treatment } \\
\text { plants }\end{array}$ \\
\hline
\end{tabular}

*Corresponding author: jerzy.kaszkowiak@utp.edu.pl 


\begin{tabular}{|c|c|c|}
\hline $\mathrm{CH}_{4}$ & $57-62 \%$ & $64-75 \%$ \\
\hline $\mathrm{CO}_{2}$ & $33-38 \%$ & $20-35 \%$ \\
\hline $\mathrm{H}_{2} \mathrm{~S}$ & $-8000 \mathrm{ppm}$ & $\leq 8000 \mathrm{ppm}$ \\
\hline $\mathrm{N}_{2}$ & $3,4-8,1 \%$ & $3-4 \%$ \\
\hline $\mathrm{O}_{2}$ & $0-0,5 \%$ & $0,5 \%$ \\
\hline
\end{tabular}

The costs of work of the cogeneration systems powered with biogas depend on outlays incurred on biogas' generation (value of substrates, costs of their transport, costs of the biogas geneation process) [6] and the costs of the units' operation (amortization, repairs, servicing). In case of failure-free operation, the outlays connected with periodical oil's exchange are one of the biggest costs. Extension of the periods between the subsequent exchanges, lowers the outlays incurred on servicing, but at the same time it may result in the motor's durability decrease [7]. The change of the content of selected compounds and chemical elements in the oil, may be also used for the motor's condition assessment. In particular the contents of copper, mangane, aluminium and iron in the engine oil prove of that [8]. However, the impact of the oil filtering system, which may to a considerable degree change the contents of impurities in the oil, should be taken into consideration.

Determination of the biogas powered motor loading's impact and the impact of the time of operation on the contents of selected metals in the engine oil, was the purpose of the studies.

\section{Materials and methods}

The studies were conducted on the group of two motors powered with biogas propelling electric current generators. The tested units had an identical construction with 12 cylinders placed in the $\mathrm{V}$ system. The engines were equipped with turbo-charging of a constant geometry. The engine cubic capacity amounted to approximately $12000 \mathrm{~cm}^{3}$, and their power quoted by the producer amounted to $380 \mathrm{~kW}$. The engines were in a very good technical condition, till the tests' commencement they had been exploited for not longer than 2 years from the moment of their production. The engines were equipped with the bypass oil filters. The highest quality dedicated synthetic oil designed for engines powered with biogas, was used for the engines' lubricating. At the time of the tests conducting, one of the engines was loaded in a constant mode, on the level of $85 \%$ nominal power at the variation not exceeding $\pm 5 \%$. The second tested engine was loaded in a variable mode at the average loading level of $65 \%$, where the range of changes of the temporary loading changed within the range from $85 \mathrm{~kW}$ to $330 \mathrm{~kW}$. The cycle of the tests each time lasted for about 800 operating hours ( \pm 10 hours). The testing cycles were repeated three times. After the end of each operating cycle, at the time of the engine oil's exchange its samples were taken for testing. There was examined the contents of iron, chromium, nickel, aluminum, copper, lead, manganese and zinc. Biogas with which the engines were powered, was generated from the wastes remaining after the treatment of municipal liquid wastes. After its generation, it was subject to purification. The impurities were removed mechanically, and the contents of sulphur and its compounds in biogas were removed. The composition of biogas was controlled on a continuous basis with a biogas analyser BIOTEX MultiPoint. The biogas' calorific value following its purification amounted from $17,8-18,1 \mathrm{MJ} / \mathrm{m}^{3}$. The composition of biogas following its treatment is presented in table 2 . 
Table 2. Main components of biogas powering engines following its treatment.

\begin{tabular}{|c|c|}
\hline $\begin{array}{c}\text { Compon } \\
\text { ent }\end{array}$ & Contents \\
\hline $\mathrm{CH}_{4}$ & $65,25 \%$ \\
\hline $\mathrm{CO}_{2}$ & $34 \%$ \\
\hline $\mathrm{H}_{2} \mathrm{~S}$ & $11 \mathrm{ppm}$ \\
\hline
\end{tabular}

The engines operated in a common, not heated room. Combustion gases were carried off outside. The temperature in the room changed within the range $15-28^{\circ} \mathrm{C}$. The view of one of the engines is presented in figure 1.

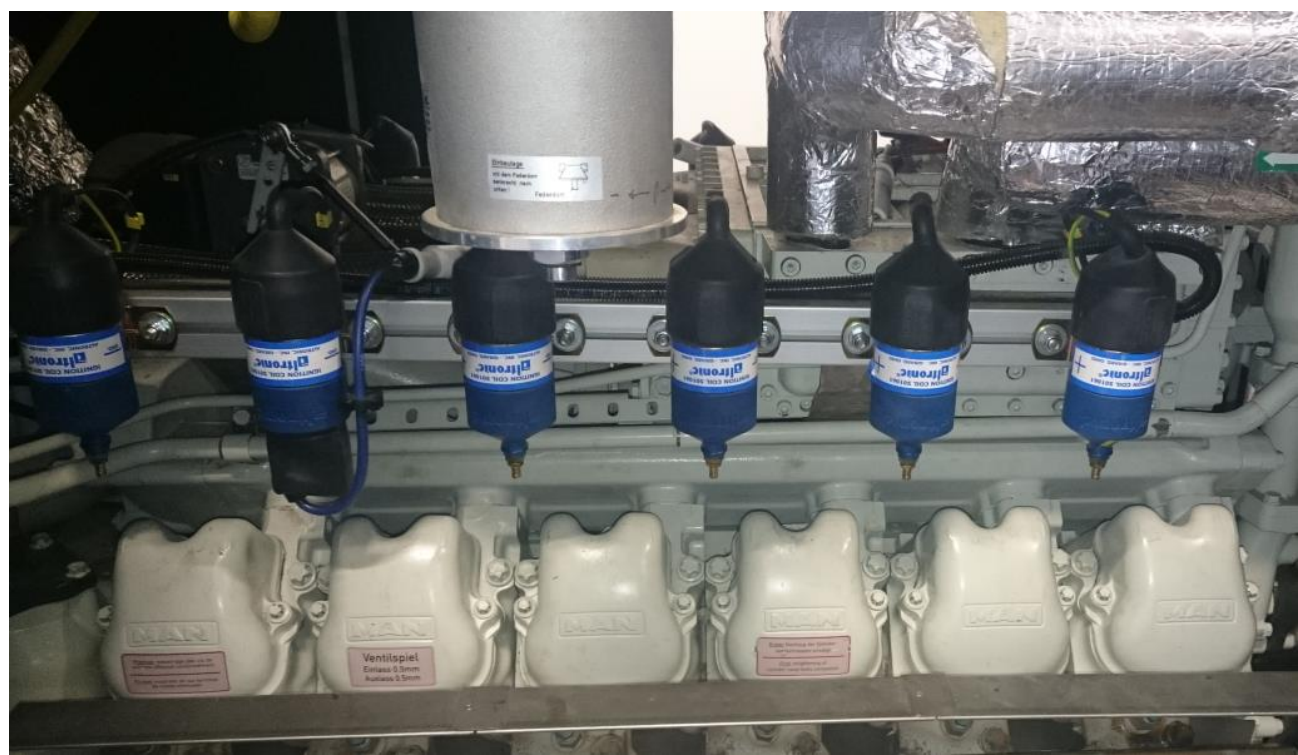

Fig. 1. View of the engine during the studies.

The obtained results were subject to statistical analysis with the Tukey's test with the use of the STATISTICA programme. In case of studying the contents of lead in oil, its presence in the oil was not found and it was not included in the further analysis description.

\section{Results}

As a result of the conducted statistical analysis, occurrence of differentiation in the contents of iron, zinc and copper in the engine oil was not found.

For an engine loaded in a continuous mode in $85 \%$ of rated power, the average contents of iron amounted to $5,0 \mathrm{ppm}$. For an engine loaded in a variable mode, at an average load of $65 \%$, the average contents of iron had a higher value and amounted to 9,3 ppm. The difference in the content of iron was statistically significant. The contents of iron depending on the mode of the engine's loading is presented in figure 2. 


\section{Contents of iron}

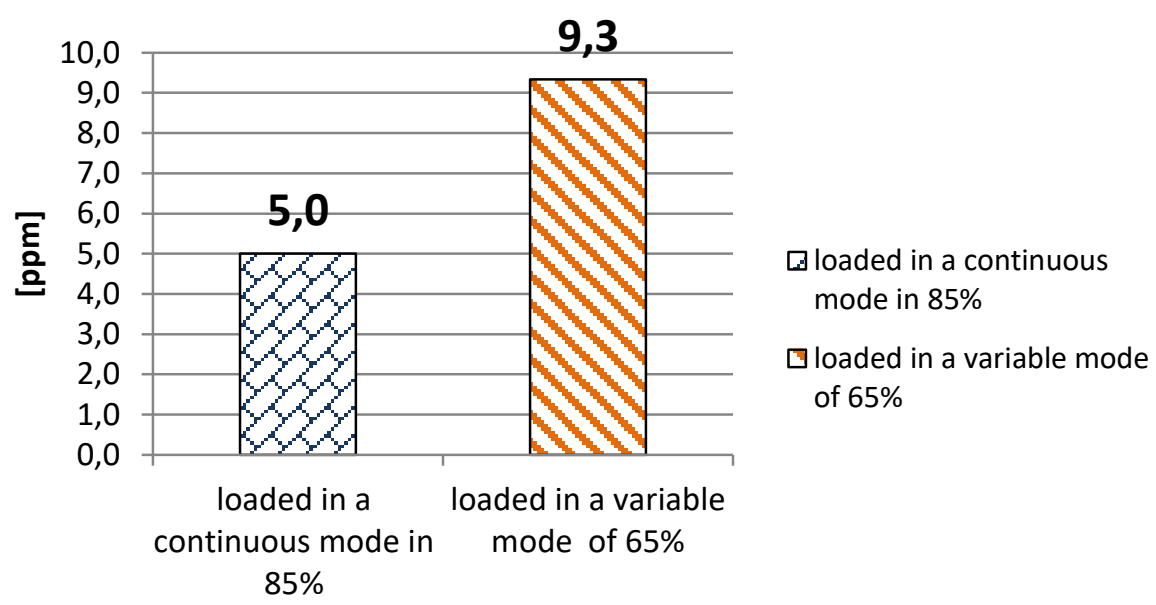

Fig. 2. The contents of iron in the engine oil depending on the mode of loading.

The average contents of aluminum in the oil for the engine loaded in a continuous mode, had a lower value and amounted to 2,0ppm. The average contents of aluminum for an engine loaded in a variable mode, had a lower value and amounted to 2,33 ppm. The differences in the contents of aluminum in the engine oil were however statistically insignificant. Their values are presented in figure 3 .

\section{Contents of aluminum}

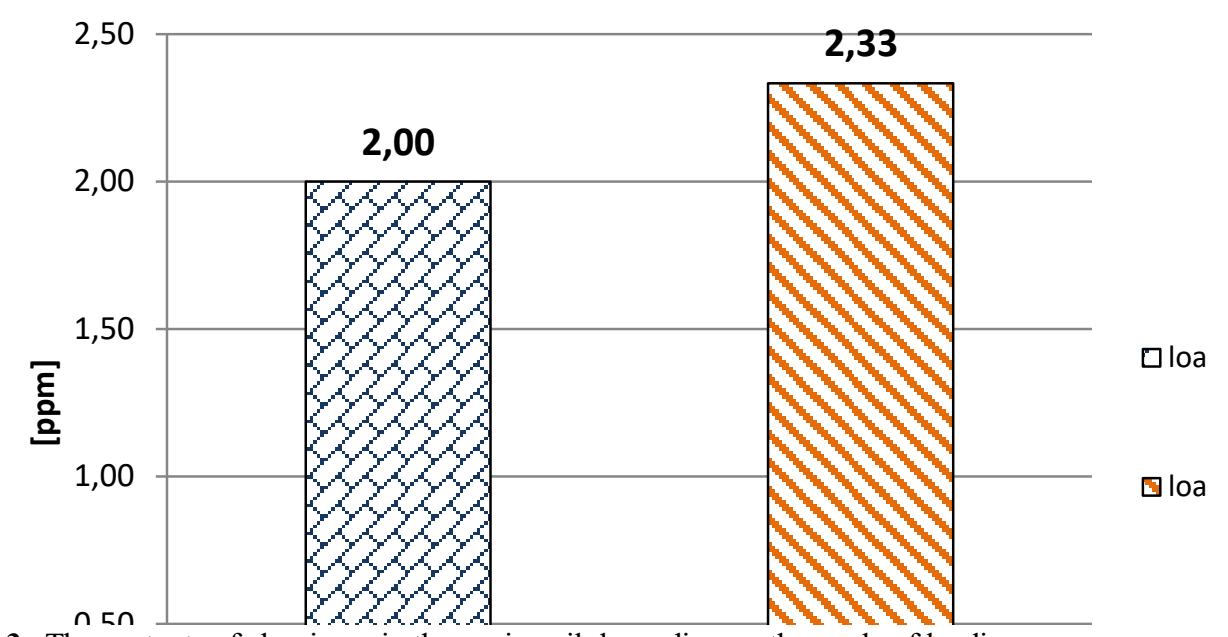

Fig. 3. The contents of aluminum in the engine oil depending on the mode of loading.

The mean contents of copper in the engine oil for an unit loaded in a continuous manner on the level of $85 \%$ of rated power, had the value of $2,33 \mathrm{ppm}$. For an engine loaded in a variable manner, at average loading of $65 \%$, the contents of copper in the oil had a higher average value and amounted to $5,33 \mathrm{ppm}$. The average contents of copper in the engine oil 
for the examined cases are presented in figure 4. The differences were statistically significant.

\section{Contents of copper}

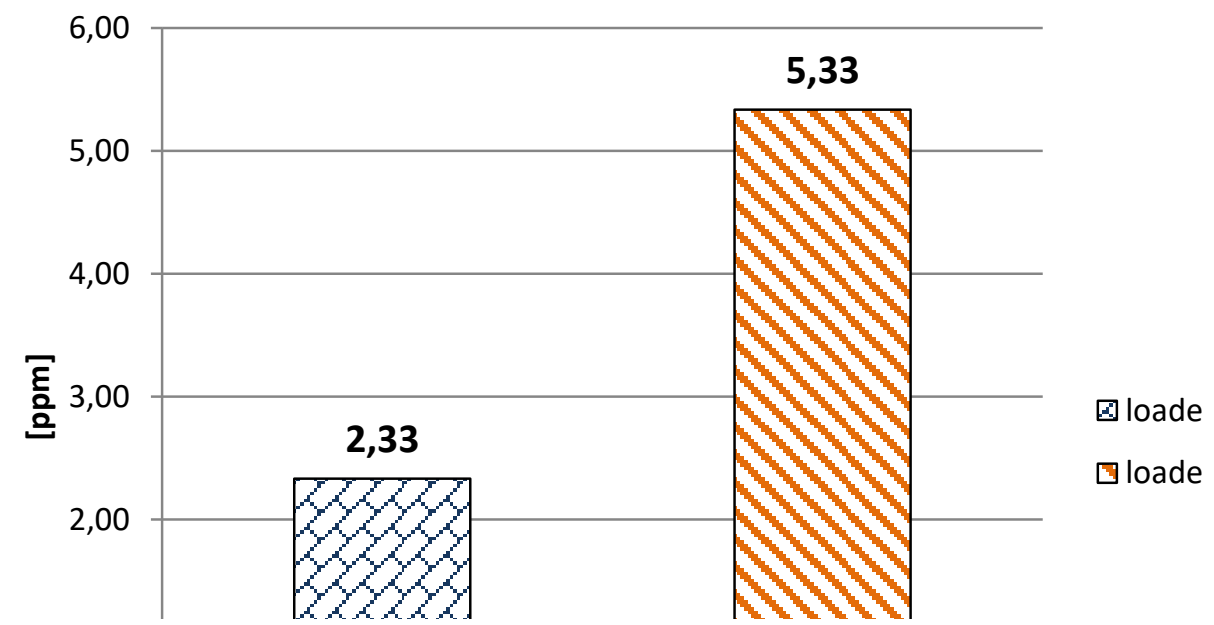

Fig. 4. The contents of copper in the engine oil depending on the mode of loading.

The contents of manganese and chromium in the engine oil were not found in both the examined cases. However, statistically significant differences occurred for the contents of zinc. The average contents of zinc in the oil for the engine loaded in a constant mode on the level of $85 \%$ of power, amounted to $356,3 \mathrm{ppm}$. For an engine loaded in a variable mode, the contents of zinc in the oil had a higher value and amounted to $389,3 \mathrm{ppm}$. The average contents of zinc in the engine oil is presented in figure 5.

\section{Contents of zinc}

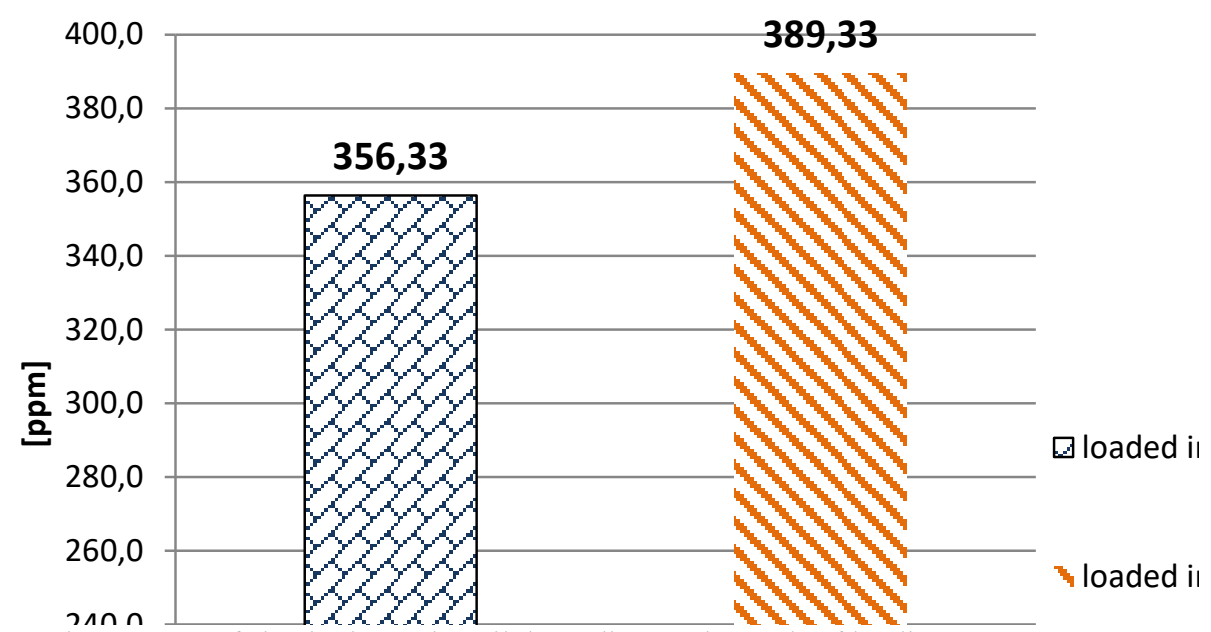

Fig. 5. The contents of zinc in the engine oil depending on the mode of loading.

For engines loaded in a constant mode and at simultaneous higher average value $(85 \%$ rated power), the contents of iron, copper and zinc in the engine oil after the period of 800 
operating hours was determined and was significantly statistically lower than for engines loaded in a smaller degree but in a variable mode (65\% rated power).

\section{Conclusions}

Presence of the examined metals in the engine oil signifies occurrence of the engine elements and its accessories' (turbo-compressor) wear and tear processes. Copper found in oil is most often the effect of abrasive wear of slide bearings' bushings of the crankshaft, distribution shaft and the turbo-compressor's bushings. The presence of iron in the engine oil signifies the piston rings, cylinder sleeves and the crankshaft's wear and tear processes. The presence of zinc in the engine oil results from its use as an anti-corrosive additive, but the increase of its contents is the effect of the wear and tear of the slide bearings' bushings in which it is the component of the bearing alloy. Zinc may also come from refining additives, but its content should in such a case decrease $[9,10]$. For a biogas-fueled engine, higher content of zinc, copper and iron engine oil was found in the case of a variable-load engine. The presence of copper and iron zinc in a $85 \%$ power-loaded engine was lower. The differences found are statistically significant. The tests carried out will be supplemented in the further research cycle by measuring the wear of selected engine components

\section{References}

1. A. Bilcan, O. Le Corre, A. Delebarre, Environ. Technol. Vol. 24 , No. 9, (2003)

2. M. Zastempowski, S. Borowski, J. Kaszkowiak, Trends in Agricultural Engineering Prague, 673-676 (2013)

3. E. Dulcet, J. Kaszkowiak, S. Borowski, J. Mikołajczak. Biosyst. Eng. Vol 3 379-384 (2006)

4. W. Czekała, S. Bartnikowska, A. Lewicka, A. Bugała, Z. Zbytek, (2016)

5. F. Annika, T. Andersson, A. Karlsson, H. Svensson, J. Ejlertsson, J. Air Waste Manage. Assoc Vol. 54 , No. 7, (2004)

6. S. Borowski, L. Knopik, M. Markiewicz-Patalon, A. Brzostek, Trends in Agricultural Engineering Prague (2016)

7. M. Janosova, A. Petrovic, V. Vozarova, et al. Conference: 23 rd International PhD Students Conference (MendelNet) (2016)

8. L. Hujo, Z. Tkac, J. Tulik et al. Adv. Mater. Res Volume: 801 137-142 (2013)

9. Z. Yang, W. Xie Fuel Process. Technol. Vol. 88, Issue 6 (2007)

10. J.XDong, Z.Shu, Tribol. Int. Vol. 31, Issue 5, (1998) 